Viscosity Index $=(60 \cdot 0-\operatorname{antilog} n) \times 3 \cdot 63$;

where

$$
n=\frac{\log U-0.4336}{\log \text { viscosity at } 210^{\circ} \mathrm{F}} .
$$

This viscosity index is a single-valued function. Furthermore, this scale does not differ fundamentally from the Dean and Davis original V.I. system betweon 0 and 100 , but corrects its anomalies above 140 .

The viscosity index scale was criticized because it is not directly connected with the temperature slope and also because it is not additive as regards mixtures; but it was pointed out that the law of mixtures for viseosity even of pure liquids is as yet not fully understood. From the viscosity index and viscosity at one temperature, it is possible by the use of charts, such as that issued by The American Society for Testing Materials, to ascertain viscosities over a range of temperature, and with the modified scale suggested in the paper this can be done with oils of very flat viscosity-temperatures such as are now being made by the employment of special additives to lubricating oils. The scale can be applied to oils with no change in viscosity with temperature which would have a viscosity index of around 200 and even to oils which show an increase in viscosity with rise in temporature. For the modified scale to be of value in characterizing some of the more recently developed lubricants for which the original viscosity index scale is not satisfactory, it must be adopted as a standard method by such bodies as the American Society for Testing Materials and the Institute of Petroleum Standardization Committee.

Dr. A. Lahiri presented a paper on "The Problem of Engine Deposits", by Dr. E. W. S. Mardles and himself. The paper is an extensive report on rheological and other colloidal studies of oils under oxidizing conditions simulating very closely those existing in internal combustion engines. The oxidizing apparatus can be used as a rotating viscometer of the Stormer type. Studies of specific viscosity have revealed the probable shapes of dispersions in aero-engine oils, while work with the rotating viscometer on oxidized oils has shown that rigidity develops slowly at first with time; then the oxidizing oil suddenly gelates when the concentration and polymerization of the oxidized products reach a critical value. The tendency of oils to keep in suspension soot or other detritus has also been studied. In general, a high degree of flocculation of carbon black, etc., results in high specific viscosity, high sedimentation-rates and volumes, high rigidities and yield values of the suspension.

In the discussion it was pointed out that performance tests on lubricating oils for use in internal combustion engines have been extensively developed using engines of different types, but it was felt that such tests are not complete unless information can be derived from the used oils in addition to that obtained from the condition of the engine after the test. The work described in the paper suggested a new and logical approach to this problem. In the selection of temperatures used for the oxidation tests described, the authors used thermocouples inserted at various points in pistons of aero-engines, and found that the temperature at which the oil functions is of the order of $200-300^{\circ} \mathrm{C}$.; and hence the fact must be faced that oxidation takes place at such tempera. tures. Within this range of temperatures there is, however, a marked difference in the behaviour of the same oil; thus for the same oil at $200^{\circ} \mathrm{C}$. gelation developed in 40 hours, whereas at $235^{\circ} \mathrm{C} .5$ hours was sufficient. For the chromatographic examination of used oils columns of 2 in. diameter and $6 \mathrm{ft}$. long have been used with various adsorption media such as activated silica.

The final paper was presented by Dr. A. S. C. Lawrence on "Lubricating Greases". Lubricating greases are mixtures of soaps dispersed in oil. If a soap is mixed with a hydrocarbon at low temperatures, it exists as a solid suspension. At a certain temperature $T_{1}$, the system assumes a gel structure which it maintains up to another critical temperature $T_{2}$, when it becomes a fluid solution of soap in the hydrocarbon. Peptizers may be used to change suspensoids of soap in oil into gels. A tentative structure of the gel by co-ordination was given. The rheology of greases was very briefly given.

Attention was directed to the paucity of information on the temperature-flow relations of greases, although such information would be of direct practical interest and also of great value in determining the energy of flow of the different phases in grease.

The importance of rate of cooling on the structure of greases was emphasized in the discussion, which largely centred about the application of knowledge gained in the investigation of soaps for pure fatty acid to commercial grease manufacture. The character of the mineral oil used is a factor of import. ance, and certain types of refined oils are unsuitable. Although the water content of greases is very low, and cannot be detected readily by electrical conductivity measurements, it plays an important part in peptization, that is, in increasing the degree of dispersion : it is possible that it acts as a hydrolyser of the soap and that the most effective peptizer is stearic or other fatty acid.

It was pointed out that although greases prepared from more than one metal may result in loss of consistency, in practice lime and soda greases and extreme pressure greases containing lead and calcium are found to be required industrially. Pure anhydrous sodium soaps of the fatty acids have probably never been prepared, although aluminium tri-stearate can be prepared and forms gels as do the other aluminium stearates.

All the papers and discussions reported here will be published in a separate volume by the Institute of Petroleum.

\section{DENTAL HEALTH IN BRITAIN}

$T$ HE Interim Report of the Interdepartmental Committee on Dentistry (Cmd. 6565. H.M. Stationery Office, 1944) records this Committee's opinion that the dental health of Britain is bad and that its effect upon general health is also bad. The dental profession itself cannot be blamed for this. Its ideals are high. They see in dentistry, not merely attention to teoth, but also that basic relation between dental disease and general ill-health which is the basis of the scheme of dental education outlined by C. Bowdler Henry (Lancet, 26, Jan. 6, 1945), who advocates a basic medical education for dental students and also the education of stomatologists who would act as consultants to dentists and would study dental problems in relation to other diseases and to the general biology of man. But the best dental profession in the world cannot operate in a vacuum; it must have the respect and co-operation of the people whom it seeks to serve; and the facts 
recorded in this report show that the British people not only do not take full advantage of the public dental services which now exist, but also they do not appreciate the effects of dental disease upon their general health.

As a preface to the discussion of this unsatisfactory position, the Committee outlines the history and present position of the dental profession and its educational and research facilities. Dental education in Britain is given in five dental schools in London, seven in the English provincial cities (Birmingham, Bristol, Leeds, Liverpool, Manchester, Newcastle and Sheffield), three in Scotland (Dundee, Edinburgh and Glasgow), one in Northern Ireland (Belfast) and four in Eire. Before the War, these schools had a capacity of 2,000-2,500 ; most of them were staffed largely by teachers on a part-time basis, paid or honorary, and some four hundred students a year entered the schools, of whom about 10 per cent were women. Students could prepare for either the B.D.S. degree or for the somewhat lower standard of the licence (L.D.S.) ; the majority took the licence, the courses for which occupied about five years, while those for the degree were rather longer. Most of the schools have some facilities for research, but most of the staff have little time for this. The dental hospitals provide treatment for the poor and clinical teaching for the students; but neither the hospitals nor the schools have enough money for expansion and improvement. Refresher courses and a limited number of hospital posts provide some post-graduate training. Figures supplied by the Government Actuary indicate that most of the dentists admitted to the register by the 1921 Act are now older than forty-five, so that there will be, in the next few years, a rapid loss of names from the Register by retirement; and the average annual rate of entry to the Dental Register in recent pre-war years in Great Britain was about 340 , while the annual rate of entry of students has fallen to below three hundred, some 10 per cent of whom do not, for various reasons, become dentists. It is therefore clear that the Register cannot be maintained even at its present strength. Even if the annual number of persons entering the profession rose to 400 between $1948-52$ and to 425 thereafter, it would still be thirty years before the present effective total of the profession would be increased. This is indeed, as this report puts it, an alarming forecast.

Nor is this Committee satisfied with the present position of ancillary dental workers, namely, dental dressers, dental attendants and dental mechanics. The dental mechanic is an essential part of any dental service, and the existing arrangements for the training of dental mechanics are inadequate.

Considering remedies, the Committee concludes that the greatest single step forward would be the creation of a single comprehensive dental service equally available to all who demand it, and paid for by the community as a whole. This service should be an integral part of the Government's national health service; it would give the dental profession its rightful place in the public estimation and would encourage the much-needed recruitment to the profession. In such a scheme certain classes of people, namely, nursing and expectant mothers, children and adolescents, require special attention, and a big expansion of dental services for school-children is one of the essential foundations of a comprehensive health service. All local authorities responsible for schemes of dental health should appoint, as some do now, a chief dental officer with adequate powers. Quotations from statements made by local authorities show that they are aware of the importance of their responsibilities in this respect.

No dentist, the report insists, should be compelled to enter the public service and all should be able tc leave it if and when they desire to do so. Dentists should also be able to engage in whole- or part-time public dental service and in any branch of it. The patient must have free choice of the dentist and liberty to change to another at will. The right tc private dental service should especially be preserved. General dental practitioner service should be broadly analogous to that of general medical practitioner service. Dental health centres should be established; they might be experimental at first, the local dentists being consulted about their organization, design and equipment; this participation by dentists in the planning of the dental health centres is emphasized by the report, which would extend it to the planning and administration of the whole dental health scheme.

The report emphasizes the importance of education of the public in dental health. A definite policy of education of the public is required, which should include high quality of dental treatment, education at the health centres, dental hygiene in the schools, the encouragement of children to accept treatment, education at maternity and child welfare centres and the supply of publicity material from central sources. The report concludes with the recommendations that suitable ex-Service men and women should be encouraged to become dentists, that dental teachers should be recalled from service as soon as possible and that dental equipment now being used in the Services should be made available for the public dental service.

The unanimity and brevity of this report enhance its value. Its recommendations should be widely known, for without the intelligent co-operation of the public no health scheme can succeed.

\section{METCHNIKOFF CENTENARY CELEBRATIONS}

\section{A} MEETING was held at the Opera House in Moscow on May 15 to celebrate the centenary of Metchnikoff's birth; it was opened by G. Miterev, the Soviet Commissar of Public Health. A great gathering of representatives of the medical profession and of bacteriology had come together to honour the memory of the great Russian man of science and philosopher.

Ilya Metchnikoff was one of the first Russian Darwinists, and proved by his experimental work the existence of general laws of evolution applying to all animal organisms. His biological research on comparative embryology led him to problems of pathology and medicine, in which he obtained epoch-making results, formulating a theory of phagocytosis. After working for a long time at the Pasteur Institute in Paris, he became head of a new school of microbiology investigating especially problems of immunity as it affects medical practice, particularly vaccination. During the latter part of his life, Metchnikoff gave much attention to the study of old age, longevity and death. His point of view was that people do not live so long as they should do, and that, by appropriate modes of living, life could be considerably lengthened. 